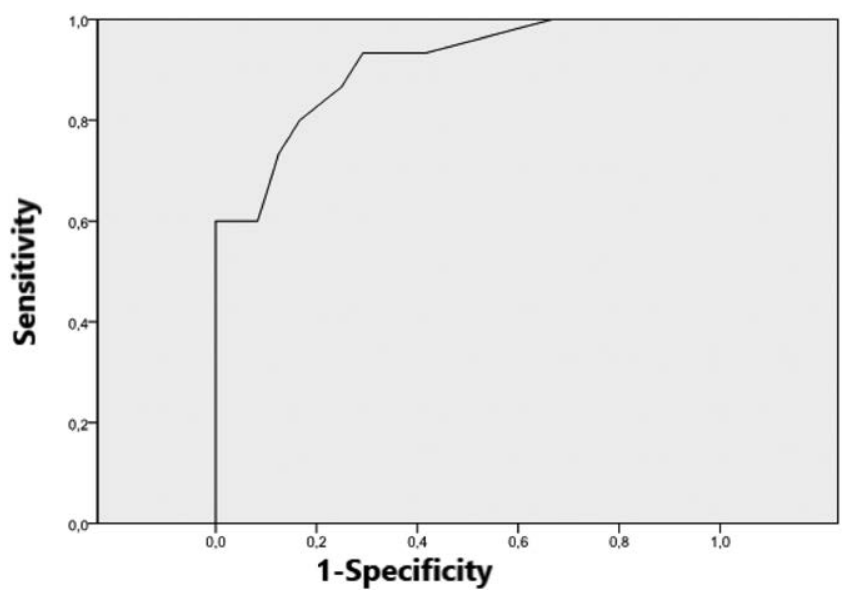

Fig. 1 ROC curve (fluid analysis as gold standard)

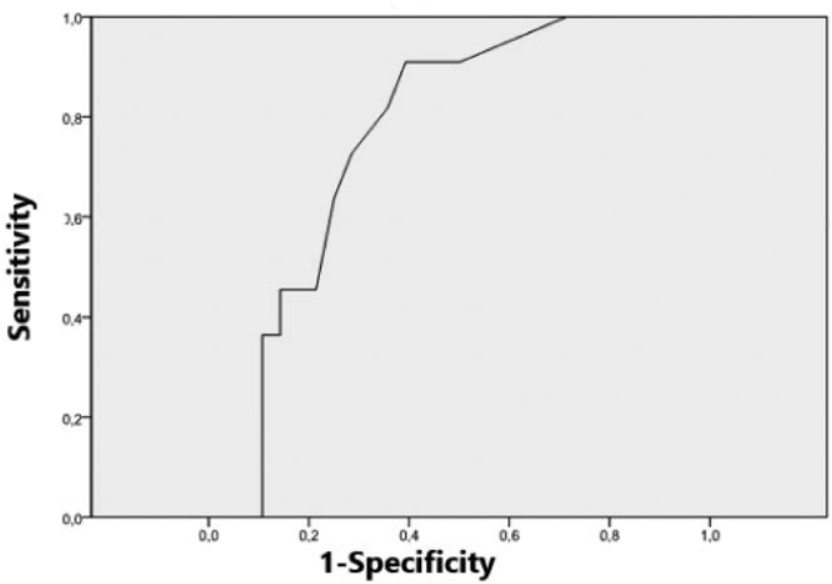

Fig. 2 Roc curve (ACR/EULAR as gold standard)

Conclusion: Although having been developed for use in primary-care, the Nijmengen score appears to be useful in patients hospitalized for acute monoarthritis in a rheumatology unit.

References:

[1] Janssens et al. A diagnostic rule for acute gouty arthritis in primary care without joint fluid analysis. Arch Intern Med 2010; 170:1120-6.

[2] Kienhorst $L$ et al. The validation of a diagnostic rule for gout without joint fluid analysis: a prospective study. Rheumatology 2015; 54:609-14.

[3] Neogi T et al. 2015 Gout Classification Criteria: An American College of Rheumatology/European League Against Rheumatism Collaborative Initiative: ACR/EULAR CLASSIFICATION CRITERIA FOR GOUT. Arthritis and Rheumatology. oct 2015;67(10):2557-68

Disclosure of Interests: : marie Schmitt: None declared, André Ramon: None declared, Paul Ornetti: None declared, jean Francis Maillefert Grant/research support from: Abbot, shugai, Roche, pfiser, BMS,, Speakers bureau: Abbot, Shugai, Roche, Pfiser, BMS

DOI: 10.1136/annrheumdis-2020-eular.5999

\section{THU0442 \\ GOUT AND HEART FAILURE IN THE US: A NATIONAL PERSPECTIVE}

G. Singh ${ }^{1}$, M. Sehgal ${ }^{2}$, A. Mithal ${ }^{3}$. ${ }^{1}$ Stanford University, Gastroenterology and Hepatology, Stanford, United States of America; ${ }^{2}$ University of California Los Angeles, Los Angeles, United States of America; ${ }^{3}$ Institute of Clinical Outcomes Research and Education (ICORE), Woodside, United States of America

Background: Heart failure (HF) is the eighth leading cause of death in the US, with a $38 \%$ increase in the number of deaths due to HF from 2011 to 2017 (1). Gout and hyperuricemia have previously been recognized as significant risk factors for heart failure (2), but there is little nationwide data on the clinical and economic consequences of these comorbidities.

Objectives: To study heart failure hospitalizations in patients with gout in the United States (US) and estimate their clinical and economic impact.
Methods: The Nationwide Inpatient Sample (NIS) is a stratified random sample of all US community hospitals. It is the only US national hospital database with information on all patients, regardless of payer, including persons covered by Medicare, Medicaid, private insurance, and the uninsured. We examined all inpatient hospitalizations in the NIS in 2017, the most recent year of available data with a primary or secondary diagnosis of gout and heart failure. Over 69,800 ICD 10 diagnoses were collapsed into a smaller number of clinically meaningfu categories, consistent with the CDC Clinical Classification Software.

Results: There were 35.8 million all-cause hospitalizations in patients in the US in 2017. Of these, 351,735 hospitalizations occurred for acute and/or chronic heart failure in patients with gout. These patients had a mean age of 73.3 years (95\% confidence intervals 73.1 - 73.5 years) and were more likely to be male $(63.4 \%)$. The average length of hospitalization was 6.1 days $(95 \%$ confidence intervals 6.0 to 6.2 days) with a case fatality rate of $3.5 \%$ (95\% confidence intervals $3.4 \%-3.7 \%)$. The average cost of each hospitalization was $\$ 63,992(95 \%$ confidence intervals $\$ 61,908$ - $\$ 66,075)$, with a total annual national cost estimate of $\$ 22.8$ billion (95\% confidence intervals $\$ 21.7$ billion - $\$ 24.0$ billion).

Conclusion: While gout and hyperuricemia have long been recognized as potential risk factors for heart failure, the aging of the US population is projected to significantly increase the burden of illness and costs of care of these comorbidities (1). This calls for an increased awareness and management of serious co-morbid conditions in patients with gout.

\section{References:}

[1] Sidney, S., Go, A. S., Jaffe, M. G., Solomon, M. D., Ambrosy, A. P., \& Rana J. S. (2019). Association Between Aging of the US Population and Hear Disease Mortality From 2011 to 2017. JAMA Cardiology. doi:10.1001/ jamacardio.2019.4187

[2] Krishnan E. Gout and the risk for incident heart failure and systolic dysfunction. BMJ Open 2012;2:e000282.doi:10.1136/bmjopen-2011-000282

Disclosure of Interests: : Gurkirpal Singh Grant/research support from: Horizon Therapeutics, Maanek Sehgal: None declared, Alka Mithal: None declared DOI: 10.1136/annrheumdis-2020-eular.3905

\section{THU0443 \\ SEASONAL VARIATIONS AND ASSOCIATED FACTORS OF GOUT ATTACKS: A PROSPECTIVE MULTICENTER STUDY IN SOUTH KOREA}

H. J. Choi ${ }^{1}$, K. W. Moon ${ }^{2}$, H. O. Kim ${ }^{3}$, Y. A. Lee ${ }^{4}$, S. J. Hong ${ }^{4}$, J. Y. Jung ${ }^{5}$, H. A. $\mathrm{Kim}^{5}$, C. H. Suh ${ }^{5}$, Y. J. $\mathrm{Ha}^{6}$, I. J. Kim ${ }^{7}$, J. Lee ${ }^{7}$, E. K. Park ${ }^{8}$, S. G. Lee ${ }^{8}, \mathrm{M}$. R. Seo ${ }^{1}$, H. J. Baek ${ }^{1}$, S. T. Choi ${ }^{9}$, J. S. Song ${ }^{10} .{ }^{1}$ Gil Medical Center, Gachon University College of Medicine, Incheon, Korea, Rep. of (South Korea); ${ }^{2}$ Kangwon National University School of Medicine, Chuncheo, Korea, Rep. of (South Korea); ${ }^{3}$ Gyeongsang National University School of Medicine, Jinju, Korea, Rep. of (South Korea); ${ }^{4}$ Kyung Hee University Hospital, Seoul, Korea, Rep. of (South Korea); ${ }^{5}$ Ajou University School of Medicine, Suwon, Korea, Rep. of (South Korea); ${ }^{6}$ Seoul National University Bundang Hospital, Seongnam, Korea, Rep. of (South Korea); ${ }^{7}$ Ewha Womans University College of Medicine, Seoul, Korea, Rep. of (South Korea); ${ }^{8}$ Pusan National University School of Medicine, Busan, Korea, Rep. of (South Korea); ${ }^{9}$ Chung-Ang University, School of Medicine, Seoul, Korea, Rep. of (South Korea); ${ }^{10}$ Chung-Ang University, School of Medicine, Seoul, Korea, Rep. of (South Korea)

Background: Gout shows a seasonal variation that widely differs among geographic areas, and we previously reported a seasonal effect on gout in Korea However, we had no information regarding changes in diet and had only limited laboratory data because this was a retrospective study in patients receiving a urate-lowering therapy. Therefore, we designed this prospective study to elucidate the seasonality and associated factors of gout attacks in Korea.

Objectives: To evaluate the seasonality and associated factors of the incidence of gout attacks in Korea.

Methods: We prospectively enrolled patients with gout attacks who were treated at nine rheumatology clinics between January 2015 and July 2018 and followed them for 1-year. Demographic data, clinical and laboratory features, and meteorological data including seasonality were collected.

Results: Two hundred-five patients (males, 94.1\%) were enrolled. The proportion of patients with initial gout attacks was $46.8 \%(n=96)$. The mean age body mass index, attack duration, and serum uric acid level at enrollment were 50.5 years, $26.1,10.2$ days, and $7.3 \mathrm{mg} / \mathrm{dL}$, respectively. Gout attacks were mos common during spring $(43.4 \%, P<0.001)$ and in March $(23.4 \%, P<0.001)$. A similar pattern of seasonality was observed in the group with initial gout attacks. Alcohol was the most common provoking factor (39.0\%), particularly during summer $(50.0 \%)$. The mean diurnal temperature change on the day of the attack was highest in the spring $\left(10.3^{\circ} \mathrm{C}\right)$, followed by winter $\left(9.1^{\circ} \mathrm{C}\right)$, summer $\left(8.1^{\circ} \mathrm{C}\right)$, and fall $\left(8.0^{\circ} \mathrm{C}\right)(P=0.027)$. The mean change in humidity between the 2 consecutive days (the day before and the day of the attack) was significantly different among the seasons $(3.4 \%$, spring; $0.2 \%$, summer; $0.4 \%$, fall; $-3.9 \%$, winter; $P=0.015$ ) One hundred twenty-five $(61 \%)$ patients completed 1 -year follow-up $(51 \%$ in the 